\title{
Relative importance of referents on pay satisfaction: A review and test of a...
}

Kenneth S Law; Chi-Sum Wong

Journal of Occupational and Organizational Psychology; Mar 1998; 71, ABI/INFORM Global pg. 47

\section{Relative importance of referents on pay satisfaction: A review and test of a new policy-capturing approach}

\author{
Kenneth S. Law* \\ Department of Management of Organizations, The Hong Kong Cniversity of Sicuce and Tecbnology, \\ Clear IV'ater Bay, Konloon, Hong Kong \\ Chi-Sum Wong \\ Department of Managemen, The Chinese University of Itong Kong \\ and \\ Providence Eniversity (Tainan)
}

\begin{abstract}
Two approaches for estimating the relative importance of various referents in affecting pay satisfaction are reviewed. The first approach uses the most frequently reported referents by the respondents as the most important referents. The logic of this approach is questioned because frequency of using a teferent is different from his/her relative importance. The second approach uses a policy-capturing method by which respondents are asked to evaluate their pay satisfaction when compared to various referents. The respondents' overall pay satisfaction is then regressed on these evaluations. "This approach may have the problem of the common method effect (i.e. the problem of common method variances between predictors and criterion) and the dominance effect (i.e. higher measurement errors for referents with nartower pay ranges). An alternative policy-capturing approach that minimizes these two limitations is suggested. Data from a sample of 106 bank clerks show that the use of the above three approaches can result in three different conclusions. Because some important methodological limitations are avoided in this new policy-capturing approach, and given the reasonable results derived from it, we concludic that this new approach should be considered for future research on pay referent selection.
\end{abstract}

$\Lambda$ fter decades of research on its dimensionality, antecedents and consequences, pay satisfaction remains a construct of interest to both scholars and practitioners. One reason for the continuing interest is its link to important employee behaviours such as absenteeism, turnover, union voting and extra-role behaviours (Heneman, 1985; Scholl, Cooper \& McKenna, 1987; Weiner, 1980). Nlthough there is much in the literature on pay satisfaction and its related constructs, the issue of pay referents remains under-researched. The selection of pay referents is an important construct closely related to pay satisfaction because social comparison is the core construct in

*Requests for reprints. 
major theories on pay satisfaction such as the relative deprivation theory (Davies, 1959), equity theory (Adams, 1963) and discrepancy theory (Lawler, 1971, 1981). Irrespective of the value of research on pay referents, there is little in the literature on the identification of possible pay referents or on their infuence on pay satisfaction decisions. Given the significance of the issue, this paper reviews the pay referents literature, comments on studies in the past, and suggests a new policy-capturing approach to estimate the relative importance of various referents in formulating pay satisfaction perceptions.

\section{Relative importance of referents and theories of pay satisfaction}

The concept of pay referents is closely linked to theories of pay satisfaction. There are two frequently quoted theories of pay satisfaction in the literature (Heneman, 1985; Wallace \& Fay, 1988): the equity theory by Adams (1963) and the discrepancy theory by Lawler $(1971,1981)$. Put into the context of pay satisfaction, Adams' equity theory argues that one compares one's job input/pay ratio with certain referents. If one's input/pay ratio is similar to the input/pay ratio of the referents, one would be satisfied with one's pay. Lawler's discrepancy model explains pay satisfaction as a function of the discrepancy between two perceptions. The first perception pertains to the feeling about how much pay one should receive with respect to some referents. The second perception is simply the feeling about how much pay one is actually receiving. One will be satisfied with one's pay if the two perceptions are identical, i.e. no perceived discrepancy.

Both the equity and discrepancy theories postulate that pay satisfaction is the result of social comparisons with respect to relevant referents. In other words, a person determines if $s$ he is satisfied with her or his pay by comparing her/himself with pay referents. According to these theories, if one has used one's family members and colleagues as referents in the past and is highly satisfied with one's pay, one may become completely dissatisfied if, for whatever reason, one suddenly switches to some other set of pay referents. Since different employees may have totally different pay referents and most individuals have multiple pay referents (Goodman, 1974), it is important for pay administrators to have a good understanding of the relative importance of different pay referents in order to ensure that the average employee is satisfied with his/her pay.

In this study, we develop a new policy-capturing approach to determine the relative importance of pay referents based on the Lawler (1981) discrepancy model of pay satisfaction. As mentioned above, Lawler's discrepancy model postulates that two distinct perceptions lead to an overall judgment of pay satisfaction. The first perception is the 'perceived amount one should receive'. One develops some references for this perceived amount by reviewing $(a)$ one's personal job inputs, $(b)$ the inputs and outcomes of referent others, and $(c)$ one's job characteristics. The second perception in Lawler's model is the 'perceived amount received'. The discrepancy model postulates that one develops this perceived amount received by comparing the pay one receives with the pay of referent others. These two pay-level perceptions are the variables addressed in this study in terms of the way in which they affect pay satisfaction. 
Studies on referent selection

Past research on pay referents shows that employees compare their pay with some referent others and that the majority use multiple referents (e.g. Dornstein, 1988; Finn \& Iee, 1972; Goodman, 1974; Hills, 1980). Most of the studies about pay referents focus on the issue of referent selection. They address issues of the factors affecting the choice of referents, such as level of professionalism, occupancy of boundary role (Goodman, 1974; Summers \& DeNisi, 1990), situational factors (Oldham, Kulik, Stepina \& Ambrose, 1986), work-group membership (Ambrose \& Kulik, 1988), perceived internal and external mobility opportunities, friendship ties in the organization, job satisfaction and perceived position relative to others in the same occupation (Dornstein, 1988), similarity of the referents (Major \& Forcey, 1985; Major \& Testa, 1989), and time (Stepina \& Perrewe, 1991).

In identifying referents, most of the studies have used a direct approach, i.e. researchers ask the respondents directly to describe their choice of pay referents or ask the respondents to select a number of referents from a given list (see, for example, Ambrose \& Kulik, 1988; Stepina \& Perrewe, 1991). These studies have made the assumption that the most frequently cited referent is the most important referent. This assumption is dubious for two reasons. First, different respondents may use different sets of referents, which may make cross-individual comparison almost impossible. For example, the finding may be that 50 per cent of the respondents compare their pay with their colleagues and supervisors, while 35 per cent of the respondents compare their pay with their colleagues and people doing similar jobs in other organizations. We can conclude that 'colleagues' is the most frequently used referent. We cannot, however, conclude that for all the respondents, on average, colleagues as a referent group is more important than other referent groups in affecting the respondents' equity perception or pay satisfaction.

Second, the frequency of comparison with a particular referent group does not necessarily mean that the referent group is important in affecting pay satisfaction. For example, an employee may always compare his or her present pay with his or her immediate supervisors in order to assess the potential value of the next promotion. This comparison, however, may have very little effect on his or her perception of pay satisfaction. Most studies using this direct approach, with the exception of Goodman's (1974), have ignored the differences in frequency of comparison and the relative importance of each referent in determining perception of pay equity and pay satisfaction.

\section{Studies investigating the relative importance of referents}

There are a limited number of empirical studies directly investigating the relative importance of different referents. After asking the respondents to indicate their pay referents in interviews, Goodman (1974) performed separate analyses on respondents who mentioned their use of seven types of referents, namely other-inside, other-outside, system-structure, system-administration, self-pay history, self-family and self-internal. Respondents' perceived equity for respective referents was coded according to their comments during the interviews. The relationship between the 
perceived equity and pay satisfaction was strongest for other-outside referents and weakest for other-inside and self-pay history referents. These analyses, however, are not a direct test of the relative importance of various referents because the sets of respondents incuded in each analysis differ with some overlapping due to the fact that the majority of respondents use multiple referents. Thus, pay administrators may not be able to conclude, on average, the relative importance of each referent group for all the respondents.

Another common technique used to estimate the relative importance of different pay referents is the policy-capturing approach. Taylor \& Vest (1992) asked 143 individuals to rate how often they used each of 17 different possible referents on a seven-point scale. These ratings were then grouped into four factors in a factor analysis, and the four resulting common factors were used to predict pay satisfaction. Factors with higher regression weights were then interpreted as the more important pay referents. As mentioned above, the major drawback of this approach is that the frequency of using different referents is not a good proxy for the relative importance of different referents.

Berkowitz, Fraser, Treasure \& Cochran (1987) used an alternative version of the policy-capturing approach. They asked respondents to rate their frequency of social comparison with various referent groups. Factor analysis was conducted on these ratings together with items measuring other constructs that may affect pay satisfaction. The relative importance of different referents is measured by factor loadings on each respective factor. Pay satisfaction was then regressed on the factor scores of different factors. Although the frequency of social comparison ratings loaded heavily on the same factor, there was little variation among the factor loadings of different referents (the factor loadings ranged from .84 to .91) and it is doubtful that the factor loadings could reflect the relative importance of each referent. It is therefore not surprising that Berkowitz et al. (1987) did not find any relationship between this social comparison factor and pay satisfaction.

As an attempt to follow Lawler's discrepancy model and measure the perceived pay differential directly, Scholl th al. (1987) asked respondents to estimate how much more (or less) they earned than specific referents. Respondents' pay satisfaction was then regressed on the estimated pay differentials with respect to different referents. However, this study controlled for the referents' education, seniority and effort because the main objective of the study was to investigate the relationship between equity perception and outcome variables, such as intention to remain and extra-tole behaviour. For example, respondents were asked to compare their pay only with the pay of their colleagues doing the same job "who had the same education, seniority and effort'. It is therefore difficult to know the relative importance of each referent in affecting pay satisfaction in this study because of the restrictive nature of the data.

Ronen (1986) used a similar policy-capturing approach and asked respondents to rate their pay satisfaction and indicate how satisfied they were when compared to (a) other employees in the same organization performing a similar job and (b) others outside the organization doing a similar job. Correlation coefficients between pay satisfaction and these two questions were used as indicators of the relative importance of the two referents. Lee \& Martin (1991) used the same approach 
except that respondents were asked to evaluate their pay satisfaction when compared to various referents. Respondents' general pay satisfaction ratings were regressed on the respondents' pay satisfaction with respect to different referents. The regression weights were interpreted as the relative importance of different referents.

There are two issues regarding these policy-capturing approaches in identifying the relative importance of pay referents that deserve further discussion. The first issue is referred to as the 'common method' effect. The problem of common method variance would be quite serere when respondents are asked about their general pay satisfaction as well as their satisfaction when compared to a series of referents using the same response scale. The average correlation coefficients for these items reported by Ronen (1986) and Lee \& Martin (1991) were 32 (.29 for the worker, .44 for the manager sample) and .37 (range .08-.59), respectively. The spurious correlation between the predictors and pay satisfaction because of common method variances will both inflate the multiple correlation and affect the regression weight estimates.

The second issue that relates to the policy-capturing approach is referred to as the 'dominance' effect. The dominance effect refers to the difference in reliability of the perceived pay differential for different referents. There are two reasons why the reliability of different referent groups would vary systematically. First, employees would have better understandings of the pay level of those who are close to them. Therefore, their estimates of market pay level for the same job would be comparatively less accurate than the estimates of the pay levels of their colleagues and best friends. As a result, reliability of the estimated pay level of referent groups that are close to the respondents would be comparatively higher than that of those who are distant to them.

Second, while an employee would know the pay level of different referent groups with similar degrees of precision, measurement errors for those referent groups with larger pay differentials would be comparatively smaller because of larger true scores as compared with the error components. As a result, the significance level of the predictive power of pay differentials with respect to different referent groups would be different simply because of different degrees of predictor reliability. To illustrate, let us assume that an employee $A$ will know the pay level of a referent group up to the nearest $\$ 100$. If the pay differential of employee $A$ and his $/$ her supervisor and colleagues are $\$ 8000$ and $\$ 1000$, respectively, a measurement of within $\$ 100$ for perceived pay level of both groups would have diametrically different effects on the reliability of these two predictors.

This study aims at reducing the common method effect and the dominance effect on the perceived pay differential. An alternative policy-capturing procedure that experimentally controls the pay differentials is suggested to accomplish both objectives.

\section{Method}

\section{Sample and procedure}

The research participants in this study were bank clerks of a medium-sized bank in Hong Kong. Questionnaires were sent to all 196 clerks, whose names and addresses were obtained from the bank's 
personnel department. The cover letter explained that the study was a survey of Hong Kong bank clerks' attitudes towards their jobs.' 'The bank clerks were asked to indicate their bank account number at the end of the questionnaire so that they would be paid HK\$30.00 (about US $\$ 4.00$ ) for their participation. A stamped reply envelope was enclosed. Altogether, 106 usable questionnaires were completed and returned, representing a response rate of 54 per cent. The average age of the participants was 28 , and 66 of the participants ( 73 per cent) were female (16 participants left the item about their sex blank). The average work experience of the participants was 4.8 years, and the average experience as a teller was 4.2 years.

\section{Measures}

Three approaches were used to estimate the relative importance of various referent groups. They are the direct approach, the inferential approach and the new policy-capturing approach. The direct approach was similar to the method used by Berkowitz et al. (1987). We simply asked the participants to estimate their frequency of using various referents. The inferential approach was similar to the policy-capturing approach used by Ronen (1986) and Lee \& Martin (1991). Participants were asked to evaluate theit pay satistaction when compared to various referents. In the new policy-capturing approach suggested in this study, the participants were put into a hypothetical sccnario in which pay levels for themselves and various referents were provided. Participants were then asked to evaluate their pay satisfaction in that situation.

The direct approach. In this approach, participants were asked to make an explicit statement about how often they compared their pay with each of five different referent groups and with their own pay in the past. The five referent groups were (1) family members and close friends, (2) other clerks in this bank (i.e. colleagues), (3) cletks in other banks (i.e. industry), (4) people with the same education and experience, and (5) their immediate supervisors. As an example, the first statement was: 'I often compare my pay with the pay of my family members and close friends'. A seven-point, Likert-type scale ranging from strongly agree (7) to strongly disagree (1) was used as the response. Before the questionnaire was sent out, the personnel manager of the bank was consulted on the five groups of referents. From her experiences of conducting exit-interviews with every employee who had left the bank, she did not think any additional referent groups were necessary.

The inferential approach. Similar to policy-capturing approaches used in the past, this inferential approach involved five statements on the participant's pay satisfaction with respect to the five referent groups as in the first approach. An example of these statements is: 'I am satisfied with my pay when I compare it with the pay of my family members or close friends'. The participants' satisfaction with respect to these five referent groups (measured by a seven-point, I.ikert-type scale with $7=$ strongly agree, 1 = strongly disagree) was then used as a predictor of their general satisfaction with their pay level using regression analysis. The general pay level satisfaction of the participants was measured using the statement: 'I am generally satisfied with my pay in this company' with a seven-point scale ranging from strongly agree (7) to strongly disagree (1).

The new policy-capturing approach. In this approach, participants were put into a hypothetical but realistic scenario. The participants were asked how satisfied they would be if given stated values of their pay and of the pay for each of the five referrent groups. An example of this approach is:

Assuming that your current monthly pay is $\$ 9729$, please indicate how satisfied you would be if the average monthly pay of the following groups of people were:

$\$ 11582$ for your tamily members and close friends

$\$ 7522$ for other clerks in your bank

$\$ 9982$ for clerks in other banks

$\$ 9637$ for people with the same education and experience as you

$\$ 19241$ for your immediate supervisor

\footnotetext{
'The questionnaire also included items about job satisfaction and job perception. Responses to these items are, however, not reported in this paper becausc they are not related to the present research question.
} 
The participants' responses were measured by a six-point, l.ikert-type scale ranging from extremely satisfied (1) to extremely dissatisfied (6). A choice of 'I don't know' was provided at the end of the scale. The differences between the hypothetical pay levels of the participant and various referent groups were then used as predictors of the six-point pay satisfaction measure in order to identify the most significant referent group.

The hypothetical pay level of the participants and their referents for each question wete random numbers generated between the market minimum (\$5300) and maximum $(\$ 13000)$ pay for clerks in Hong Kong (WYATT, 1993). Higher hypothetical pay levels for the person's immediate supervisor were used to reflect the reality. These randomly gencrated pay levels, although hypothetical, were very realistic because actual market pay ranges in the banking industry were used. Since the pay levels in the scenario were randomly and independently generated, each participant was responding to a unique combination of pay differentials. No two participants had the same hypothetical pay level for the same referent group.

Since actual pay differentials were used in this approach instead of perceived satisfaction with respect to different referent groups, predictor variables in the regression equation were not perceptual measures. Therefore, they would not have common method variances with the perception of pay satisfaction. The dominance effect was controlled for in this approach by informing the respondents of the actual average pay for different referent groups directly. Because respondents did not need to estimate pay levels for different referents, possible variations in estimation accuracy of different referent groups were eliminated.

The pay range used for generating the random pay level of the four referent groups except supervisor was set to the industry's actual pay range because most clerks in Hong Kong are young secondary school graduates whose friends mostly have the same educational background. In addition, bank clerk in Hong Kong is an occupation that is famous for its high turnover. As a result, banks are forced to follow closely the market pay rate because moving from one bank to another is such an easy task for the cletks. Given the characteristics of the sample job, it is argued that the industry's pay range was a good proxy of the actual pay ranges of the four referent groups.

Finally, although we have designed the study based on Lawler's discrepancy model and used pay differences with respect to different refcrent groups as predictors of pay satisfaction, we realized it would also be interesting to study other possible proxies of pay differentials. For example, Wallace \& Fay (1988) drew on the equity theory and argued that employees might be using the ratio of their pay to teferent's pay as a criterion of judging whether their pay was equitable. $A$ s a result, we also tested the effect of these pay ratios with respect to different referent groups on pay satisfaction of the respondents.

\section{Results}

\section{The direct approaid}

Results of the direct questions on the frequency of using each of the five pay referent groups are listed in Table 1, which shows the means, standard deviation and mean differences of the participants' frequencies of using different referent groups. For a direct comparison with past studies in referent choice, we recoded the participants' responses to the five questions into two categories: whether they used referent groups or not. If a participant answered 'slightly agree', 'agree' or 'strongly agree' on an item, $\mathrm{s} / \mathrm{he}$ was treated as one using that specific referent group. If a participant answered 'slightly disagree', 'disagree' and 'strongly disagree' on an item, $s$ / he was recoded as not using that referent group. Table 2 contains the frequencies of each set of referent group(s) after recoding.

Consistent with research results in the past, Tables 1 and 2 confirm that the majority of participants use multiple referents when comparing their pay with others. The frequencies reported in Table 2 are consistent with studies in the pay 
Table 1. Mean, standard deviation and differences in perceived frequency of using different referent groups

\begin{tabular}{|c|c|c|c|c|c|c|}
\hline & \multirow[b]{2}{*}{ Mean } & \multirow[b]{2}{*}{ SD } & \multicolumn{4}{|c|}{$\begin{array}{l}\text { Mean differences in perceived } \\
\text { frequency of using different } \\
\text { referent groups }\end{array}$} \\
\hline & & & $\mathrm{COL}$ & IND & QUA & SUP \\
\hline Family/close friends & 3.92 & 1.63 & .00 & -.12 & -.05 & $.67^{* * *}$ \\
\hline Colleagues (COL) & 3.92 & 1.51 & & -.12 & -.05 & $.67 * * *$ \\
\hline Industry (IND) & 4.04 & 1.49 & & & .07 & $.79 * * *$ \\
\hline Same qualification (QUA) & 3.97 & 1.55 & & & & $.72^{* * *}$ \\
\hline Supervisor (SUP) & 3.25 & 1.43 & & & & \\
\hline
\end{tabular}

$* * * p<.01$.

referents choice literature. Table 1 shows that when making pairwise $t$ tests of the differences between the mean ratings, only mean ratings for 'use of supervisor as pay referent' are significantly different from ratings for other referent groups. This implies that the participants would have an equal tendency to use the other four referent groups.

To examine the relative importance of each referent group by this direct approach, the participants' general pay level satisfaction was regressed on the frequency ratings for the five referent groups. The results are shown in column 1 of Table 3. Similar to the findings of Berkowitz et al. (1987), the frequency of comparisons does not show any relationship with general pay satisfaction.

\section{The inferential approach}

Column 2 of Table 3 shows the regression of general pay level satisfaction on pay satisfaction measures with respect to the five referent groups. Regression weights for colleagues $(\beta=.33)$, family and close friends $(\beta=.29)$ and supervisor $(\beta=.22)$ are statistically significant $(p<.05)$. A direct interpretation of these results would be that clerks in the same bank (colleagues) are the most important referent affecting pay level satisfaction. Family members and close friends as well as supervisors are also important pay referents. Comparatively speaking, tellers in other banks and people with the same education and experience are less important referents.

The common method effect of using this approach can be seen in Table 4, which shows the correlation among the values for pay satisfaction with respect to various referent groups. The correlations range from .29 to .60 with an average of .49 . The three significant referents found in the regression analysis (column 2 of Table 3 ) are the three with the smallest average correlation with the other referents. There is some indirect evidence of the dominance effect from the data as well. As expected, the estimated pay level and range of the supervisor referent group are significantly 
Table 2. Result of recording frequency of referent choice

\begin{tabular}{lcc}
\hline & $\begin{array}{c}\text { Number of } \\
\text { respondents }\end{array}$ & $\begin{array}{c}\text { Percentage of } \\
\text { respondents }\end{array}$ \\
\hline $\begin{array}{l}\text { No referent } \\
\text { Self-only (past pay) }\end{array}$ & 30 & 28.3 \\
Internal only & 9 & 8.5 \\
$\quad$ Supervisor & 2 & 1.9 \\
$\quad$ Colleagues & 2 & 1.9 \\
External only & & 3.8 \\
$\quad$ Family/close friends & 4 & 2.8 \\
Industry & 3 & 2.8 \\
$\quad$ Same qualification & 3 & 0.9 \\
Two referents & 1 & 1.9 \\
$\quad$ Internal & 2 & 1.9 \\
$\quad$ External & 2 & 1.9 \\
Self and internal & 2 & 0.9 \\
$\quad$ Self and external & 1 & 7.6 \\
$\quad$ Internal and external & & 13.2 \\
Three referents & & \\
$\quad$ Internal and external & 14 & 6.6 \\
Self, internal and external & & 15.2 \\
Four referents or more & 7 & \\
$\quad$ Internal and external & 16 & \\
Self, internal and external & & \\
\hline
\end{tabular}

greater than those of the other referent groups. Since the bank clerks would possibly know the pay levels of various referent groups with a similar degree of precision in Hong Kong, the results lead to the conclusion that the relative measurement errors of the supervisor group would be smaller than the others in this sample.

\section{The new policy-capturing approach}

Column 3 of Table 3 shows the regression analysis for the new policy-capturing approach. That is, the participants' pay level satisfaction was regressed on pay differentials in the hypothetical scenario. As with the second approach, colleagues as a referent group are also identified as most important in affecting pay level satisfaction $(\beta=.34)$. People with the same education and experience are also an important referent of pay satisfaction $(\beta=.26)$. However, family and close friends as well as supervisors are not significant referent groups in this analysis. Since the pay levels of the respondents as well as the referents were randomly generated, the common method effect was minimized. On the other hand, the dominance effect was eliminated because respondents are provided with the actual pay level of each referent group. 


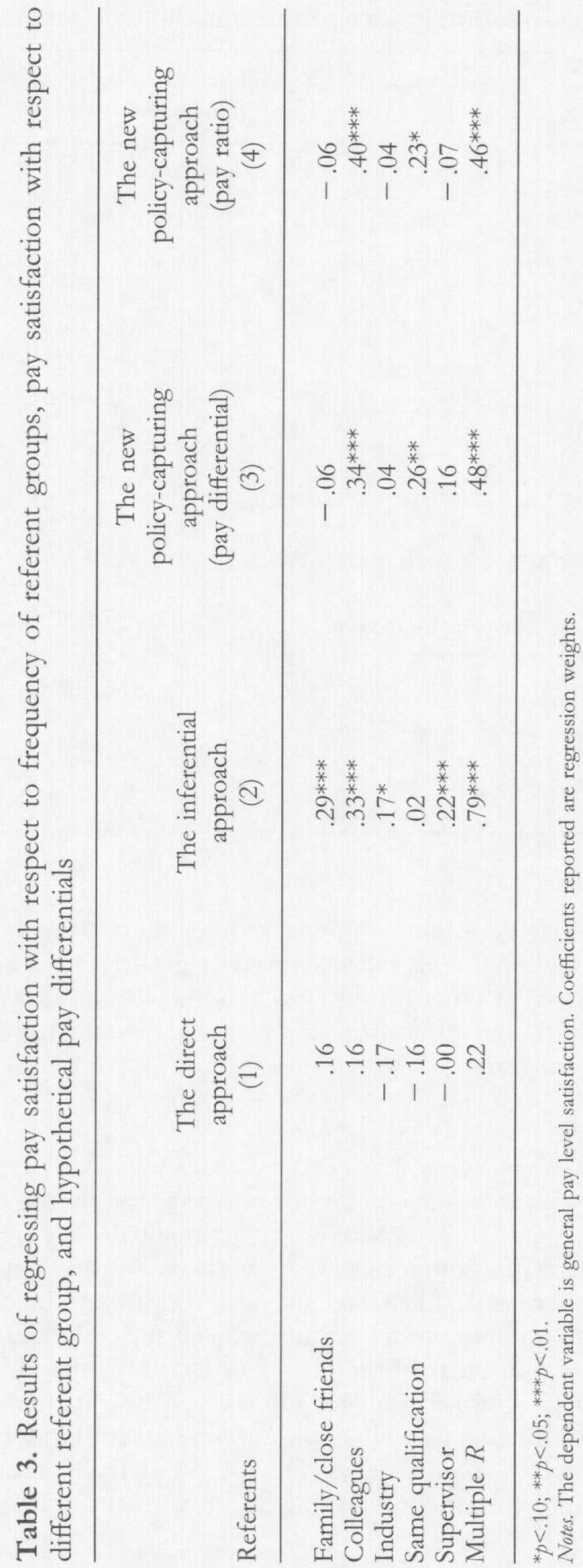


Table 4. Correlation between the pay satisfaction with respect to various referent groups

\begin{tabular}{lllllll}
\hline & $\begin{array}{c}\text { Average correlation } \\
\text { with the other four } \\
\text { referent groups }\end{array}$ & COL & IND & QUA & SUP \\
\hline Family/close friends & .47 & $.48^{* * *}$ & $.54^{* * *}$ & $.57^{* * *}$ & $.29^{* * *}$ \\
Colleagues (COL) & .50 & & $.60^{* * *}$ & $.48^{* * *}$ & $.45^{* * *}$ \\
Industry (IND) & .55 & & $.60^{* * *}$ & $.41^{* * *}$ \\
Same qualification (QUA) & .53 & & & & $.45^{* * *}$ \\
Supervisor (SUP) & .40 & & & & \\
\hline
\end{tabular}

*** $p<.01$.

Three observations can be made from column 3 of Table 3 . First, after minimizing the dominance effect on perceived pay, the referent group of family members and close friends turns out to be insignificant. In contrast, another referent group (people with the same qualifications) emerges as a significant referent group. Second, it is interesting that when the dominance cffect was controlled for, supervisors turn out to be an insignificant referent group.

Third, the fact that the multiple correlation of the inferential approach $(R=.79)$ is much higher than that of the new policy-capturing approach $(R=.48)$ is good evidence for the existence of the common method effect. Since the respondents rated their general pay satisfaction as well as their pay satisfaction with respect to different referents, the problem of common method variance creates spurious correlations among the predictors and criterion variables and leads to a much higher multiple correlation in the regression equation.

Finally, the results of using pay ratios with respect to different referent groups instead of pay differentials are shown in column 4 of Table 3 . It is cleat from column 4 that very similar results are obtained when pay ratios are used instead of pay differentials as predictors of pay satisfaction.

\section{Discussion}

This study reviews the pay referents choice literature and comments on two approaches in estimating the relative importance of various referents in affecting pay satisfaction. It attempts to compare these two approaches with an alternative policy-capturing approach that by design minimizes the limitations of the two earlier approaches. The results show that the use of different approaches can give quite different conclusions.

Consistent with the finding of Berkowitz et at. (1987), when directly asking individuals about their frequencies of using different referent groups the first approach), these frequency ratings do not correlate with pay satisfaction. Therefore, 
future research should make a sharp distinction between the frequency of comparison and the relative importance of various referents.

When using pay satisfaction with respect to various referent groups to predict general pay level satisfaction (the second approach), colleagues, family members and supervisors were identified as important referents. However, with evidence of the existence of the common method effect and the dominance effect, the conclusions from this approach are dubious.

When a hypothetical scenario of pay differentials was presented to the participants (the third approach), colleagues and people with the same education and experience were identified as the most important referents. We believe the conclusion of this approach is most valid because it minimizes the common method effect and the dominance effect by design. The referents identified are also consistent with the sample characteristics. The bank clerks are relatively young with the educational background (high school graduate) suitable for a variety of clerical positions in Hong Kong. In fact, experience as a bank clerk is regarded as equivalent to a general clerk in a lot of organizations. Therefore, colleagues and people with the same education and experience appear to be reasonable referents in this case. In addition, the result from the inferential approach that the supcrvisot is an important referent group seems strange. Hong Kong is a highly capitalistic city with huge pay differentials across organizational levels. As a result, a significantly higher pay for supervisors would be accepted as a fact of life for many employees. Therefore, results from the new policy-capturing approach that show that the supervisor is not an important referent seem to be reasonable for this particular sample. Considering the above discussion from both technical and contextual viewpoints, we believe that this new policy-capturing approach could be considered for future researchers and practitioners in estimating the relative importance of various referents.

There are, however, some possible limitations that may affect the results of this study. First, although the issue of common method variance has been minimized in our new approach, the correlation between some predictors can still be high because the actual pay differential between the respondent and some referent groups such as colleagues and industry could be quite high. This may lead to the argument that the results of the regression analysis will be affected by multicollinearity among the predictors. While acknowledging that this may be a possible problem of the policy-capturing approach in general, we would also emphasize that this is a characteristic of the sample under study and is merely a reflection of the reality. As discussed in the Method section, the actual pay differential between a clark and his or her colleagues, clerks in other banks and his or her friends would be quite similar in Hong Kong. A moderate correlation among these predictors is, therefore, a reflection of the reality in which negative effects should not be emphasized.

Second, in order to focus our efforts on the comparison of the three approaches, this study investigated only the relative effect of different possible pay referents on one dimension of pay satisfaction, namely pay level. Other dimensions of pay satisfaction, e.g. pay rise, pay system/administration and benefits (Heneman, 1985; Scarpello, Huber \& Vandenberg, 1988) were not considered. Future research may apply this methodology to these dimensions and may perhaps apply it to other social comparison research as well. 
Third, as a general limitation of all policy-capturing approaches, significance of different referents in the regression analysis is subject to possible specification errors. If, for example, some very important pay referents are missed in the new policy-capturing approach, the results may be completely different when this missed pay referent is added into the regression equation. In addition, if some other important determinant of pay satisfaction is missed, the results may also be biased. As a result, future research using this policy-capturing approach should consider all important determinants of pay satisfaction.

\section{References}

Adams, J. C. (1963). Toward an understanding of inequity. Joumal of Abnormat and Social Psychology, 67, $422-436$.

Ambrose, M. L. \& Kulik, C. T. (1988). Referent sharing: Convergence within workgroups of perceptions of equity and referent choice. Human Relations, 41, 697-707.

Berkowitz, L., Fraser, C., Treasure, F. P. \& Cochran, S. (1987). Pay, equity, job gratifications, and comparisons in pay satisfaction. Joumal of 1pplied Psychology, 72, 544-551.

Davies, J. C. (1962). Towards a theory of revolution. American Saciological Reriem, 27, 5-19.

Dornstein, M. (1988). Wage reference groups and their determinants: $A$ study of blue-collar and white-collar employees in Israel. Journal of Occupational Psycbology, 61, 221-235.

Finn, R. H. \& Lee, S. M. (1972). Salary equity: Its determinants, analysis and correlates. Journal of Applied Psychology, 56, 283-292.

Goodman, P. S. (1974). An examination of referents used in the evaluation of pay. Organizational Bebalior and Human Performance, 13, 170-195.

Heneman, H. G. III (1985). Pay satisfaction. Research in Personnet and Human Resources Management, 3, $115-139$.

Hills, F. S. (1980). The relevant other in pay comparisons. Industrial Relations, 19, 345-351.

Lawler, E. E. III (1971). Pay and Organizational Effectiveness: A Psychological Revien. New York: McGraw-Hill.

Lawler, E. E. III (1981). Pay and Organization Development. Reading, MA: Addison-Wesley.

Lee, R. T. \& Martin, J. E. (1991). Internal and external referents as predictors of pay satisfaction among employees in a two-tiet wage sctting. Journal of Occupational Psychology, 64, 57-66.

Major, B. \& Forcey, B. (1985). Social comparisons and pay evaluations: Preferences for same-sex and same-job wage comparisons. Joumal of Experimental Social Psycbology, 21, 393-405.

Major, B. \& Testa, M. (1989). Social comparison processes and judgments of entitlement and satisfaction. Joumal of Experimental Social Psybology, 25, 101-120.

Oldham, G. R., Kulik, C. T., Stepina, L. P. \& Ambrose, M. T. (1986). Relations between situational factors and the comparative referents used by employees. Academy of Management Journal, 29, $599-608$.

Ronen, S. (1986). Equity perception in multiple comparisons: A field study. Human Relations, 39, $333-346$.

Scarpello, V., Huber, V. \& Vandenberg, R. J. (1988). Compensation satisfaction: Its measurement and dimensionality. Journal of Applied Psychology, 73, 163-171.

Scholl, R., Cooper, F. \& McKenna, R. (1987). Referent selection in determining equity perceptions: Differential effects on behaviotal and attitudinal outcomes. Personnel Psychology, 40, $113-125$.

Stepina, L. P. \& Perrewe, P. L. (1991). The stability of comparative referent choice and feelings of inequity: A longitudinal field study. Joumat of Organizational Bebavior, 12, 185-200.

Summers, T. P. \& De Nisi, A. S. (1990). In search of Adam's other: Reexamination of referents used in the cvaluation of pay. Human Relations, 43, 497-511.

Taylor, G. S. \& Vest, M. J. (1992). Pay comparisons and pay satisfaction among public sector employees. Public Personnel Management, 21, 445-454. 
Wallace, M. J. \& Fay, C. H. (1988). Campensation Theory and Practice, 2nd ed. Boston, MA: PSW-Kent. Weiner, $\mathrm{N}$. (1980). Determinants and bchavioral consequences of pay satisfaction: $A$ comparison of two models. Persannel Psychology, 33, 741-757.

WYATT (1993), WY 1TT Salary and Bencfits Surveg, for Bankers and Financial Institutions (1993) August.

Received 3 Ocober 1994; rovised lersion receined 12 Warth 1997 